\title{
Prevalence and relationship between metabolic syndrome and risk of cardiovascular disease: Evidence from two population-based studies
}

\author{
Asiiat S. Alieva a, b, *, Elena Olmastroni ${ }^{\mathrm{b}}$, Olga V. Reutova ${ }^{\mathrm{a}}$, Oxana P. Rotar ${ }^{\mathrm{a}}$, \\ Alexandra O. Konradi a, Evgeny V. Shlyakhto a, Andrea Baragetti c, d, Liliana Grigore ${ }^{\text {d, e }}$, \\ Fabio Pellegatta ${ }^{\text {d, e }}$, Manuela Casula ${ }^{\text {b, e, Elena Tragni }}{ }^{\text {b }}$, Alberico L. Catapano b, e \\ a Almazov National Medical Research Centre, Saint Petersburg, Russia \\ ${ }^{\mathrm{b}}$ Epidemiology and Preventive Pharmacology Service (SEFAP), Department of Pharmacological and Biomolecular Sciences (DisFeB), University of Milan, \\ Milan, Italy \\ ${ }^{\mathrm{c}}$ Department of Pharmacological and Biomolecular Sciences (DisFeB), University of Milan, Milan, Italy \\ d SISA Centre, Bassini Hospital, Cinisello Balsamo, Milan, Italy \\ e IRCCS MultiMedica Hospital, Sesto S. Giovanni, Milan, Italy
}

\section{Keywords:}

Epidemiology

Systematic COronary risk evaluation

Metabolic syndrome

\begin{abstract}
A B S T R A C T
Background and aim: The metabolic syndrome (MetS) has become one of the most important clinical issues in the cardiovascular field for this decade because of the marked increase in cardiovascular (CV) risk associated with a clustering of risk factors. The aim of the current study was to evaluate the relationship between MetS and its components and cardiovascular disease (CVD).

Methods: This population-based cross-sectional study was based on data from two studies carried out in Russia (ESSE-RF) and Italy (PLIC). One sample from each cohort was selected, matching individuals by sex and age. A comparison between samples of MetS components distribution and CV risk, according to SCORE chart, has been conducted.

Results: A total of 609 individuals (mean [SD] age 55 [8] years, about 39\% males) for each cohort were selected. Almost half of PLIC cohort participants belonged to the moderate CV risk group ( $47 \%$ vs $27 \%$ ), while in ESSE-RF cohort a relatively higher prevalence of individuals classified in the high and very high risk group was observed (19\% vs $11 \%, 21 \%$ vs $6 \%$, respectively). Overall, $43 \%$ of ESSE-RF participants were diagnosed with MetS, compared with the $27 \%$ of PLIC members (the difference in prevalence becomes $37 \%$ vs $21 \%$, considering a more conservative cut-off for waist circumference). Both cohorts showed a trend towards the increase of MetS components moving from the lowest to the highest $\mathrm{CV}$ risk class, with a high prevalence of patients with four or five MetS determinants allocated in the high/very high CV risk group.

Conclusions: Developing effective public health strategies for the prevention, detection and treatment of MetS should be an urgent priority to reduce the burden of CVD, not only in subjects at high/very high CV risk, but also in those characterized by a lower risk, as even rare CV events that come from low risk group bring a tangible burden to healthcare systems.
\end{abstract}

() 2021 The Authors. Published by Elsevier B.V. This is an open access article under the CC BY-NC-ND license (http://creativecommons.org/licenses/by-nc-nd/4.0/).

\section{Introduction}

Precise identification of cardiovascular (CV) risk and cardiovascular disease (CVD) prevention are recognised as a key public health issue based on the WHO data about CVD mortality [1].

\footnotetext{
* Corresponding author. Almazov National Medical Research Centre, Saint Petersburg, Russia.

E-mail address: alieva_as@almazovcentre.ru (A.S. Alieva).
}

Different approaches and risk assessment systems are used to evaluate cardiovascular (CV) risk in order to predict CV events. Since 2003, the Systematic COronary Risk Evaluation (SCORE) system has been recommended in European countries, as it is based on large, representative European cohort datasets [2]. And nowadays, according to the current European Guidelines on cardiovascular disease prevention in clinical practice 2016 [2], ESC/ESH Guidelines for the management of arterial hypertension 2018 [3], and ESC/EAS Guidelines on dyslipidaemias 2019 [4], the SCORE system seems to 
be one of the most evidence-based tool for an individual's 10-year risk prediction of fatal CVD. The majority of SCORE components (except age) are modifiable and well-established CV risk factors that are needed to be managed to optimally reduce $\mathrm{CV}$ risk, regardless of patients' CV risk category. For instance, for patients in the low-CV risk class, the key question is a more precise risk identification, as even rare CV events that come from low risk group bring a tangible burden to healthcare systems, especially if a high number of subjects are classified as low-risk individuals. On the other side of the $\mathrm{CV}$ risk classes, among high/and very high $\mathrm{CV}$ risk subjects, nowadays the majority of them still do not achieve targets established by guidelines of blood pressure (BP), low-density lipoprotein cholesterol (LDL-C) and glucose levels [5]. Thus, optimization of prevention strategies is needed that might bring a positive impact on CV mortality on a population level.

Other approaches for CV risk stratification in patients with specific conditions are under discussion in order to predict CV risk more precisely, preserving feasibility and cost-effectiveness that are critically important in primary care. Based on the prevalence in different populations and its impact on CV risk, one of the most important cluster of conditions that needs to be taken into consideration is the metabolic syndrome (MetS). The risk factors associated with this syndrome are primarily well known - hypertension, dyslipidemia (high triglycerides [TG] and lower highdensity lipoprotein [HDL]), elevated fasting blood glucose, and abdominal obesity. A range of studies demonstrated that MetS, defined by the presence of at least three of the above criteria, remains a predictor of CVD [6-8], mainly because the pathogenesis of MetS involves both genetic and acquired factors that contribute to the final pathway of inflammation that leads to CVD.

In this context, the identification of the distribution of wellknown traditional CV risk factors in different populations and in different $\mathrm{CV}$ risk group category, may provide a more accurate approach within prevention strategy programs.

Based on data of two population-based studies in Italy and Russia, the aim of this sub-study was to describe the distribution of SCORE components, MetS criteria, and the relationship between them, in order to raise the question of more target-oriented and personalized prevention approaches.

\section{Materials and methods}

\subsection{Participants}

This study has been based on data from ESSE-RF and PLIC studies, which have been extensively described elsewhere [9-12].

ESSE-RF (Epidemiology of cardiovascular diseases in different regions of Russia) is a cross sectional study in 13 Russian regions aiming at investigating prevalence of risk factors and evaluating contribution of traditional and new risk factors into morbidity and cardiovascular mortality in the population of Russian Federation. As a Saint-Petersburg part of this study, 1600 apparently healthy participants aged 25-65 years were randomly selected in 2012. All participants signed informed consent and filled in the questionnaire regarding risk factors, concomitant diseases and therapy, range of laboratory tests, including fasting lipids and glucose (Abbott Architect 8000).

PLIC (Progression of the Intima Carotid Lesions) study is an ongoing observational, cross-sectional and longitudinal study of subjects enrolled on a voluntary basis in 1998-2000. The study was conducted by the Center for the Study of Atherosclerosis of Bassini Hospital (Cinisello Balsamo, Milan) in coordination with the Epidemiology and Preventive Pharmacology Centre (SEFAP) of the University of Milan. Subjects enrolled in the study undergo periodic visits (4 planned visits) to collect data about patient-reported personal and familial pathological history, lifestyle habits, clinical parameters, and drug therapies, together with blood sample to measure lipid and glycaemic profiles.

\subsection{Measurements and data analysis}

For the purpose of this study, among subjects recruited for the PLIC cohort, those who underwent the fourth visit $(n=1444)$ were selected and matched to ESSE-RF subjects (ratio 1:1) by sex and age ( \pm 3 years).

The comparison analysis between samples was based on demographic information, smoking, BP, as well as on lipid profile and glucose level. Antidiabetic, antihypertensive, and statin therapies were also evaluated. In both samples, the prevalence of diabetes mellitus and hypertension were defined in case of self-reported specific drug use, biochemical/vital parameters with levels higher than the cut off for the diagnosis ( $140 \mathrm{~mm} \mathrm{Hg}$ for SBP or/and $90 \mathrm{~mm}$ $\mathrm{Hg}$ for DBP, and $126 \mathrm{mg} / \mathrm{dL}$ for glucose), or anamnesis. Prevalence of different $\mathrm{CV}$ diseases in the two cohorts was also defined based on self-reported history of stroke, transient ischemic attack, coronary heart disease (CHD), including acute myocardial infarction, angina, silent ischemia, or percutaneous transluminal coronary angiography.

A comparison between samples of MetS distribution has been also conducted. Following the scientific criteria of metabolic syndrome [13], all participants included in the MetS group had the coexistence of at least three factors characterizing metabolic syndrome: triglyceride levels $\geq 150 \mathrm{mg} / \mathrm{dL}$ (or taking a drug treatment for elevated triglycerides has been considered as an alternate indicator), blood pressure $\geq 130 / 85 \mathrm{mmHg}$, fasting glucose $\geq 100 \mathrm{mg}$ / $\mathrm{dL}$, reduced HDL-C $(<40 \mathrm{mg} / \mathrm{dL}$ for men and $<50 \mathrm{mg} / \mathrm{dL}$ for women, or taking a drug treatment for reduced HDL-C has been considered as an alternate indicator), or having elevated waist circumference ( $\geq 94 / 80 \mathrm{~cm}$ [Caucasian recommended waist circumference threshold for abdominal obesity] or $\geq 102 / 88 \mathrm{~cm}$ [European recommended threshold] for men and women, respectively). CV risk stratification of patients was conducted according to SCORE chart. SCORE was calculated as previously described, according to individuals underlying risk for CHD, including age, cholesterol, smoking and systolic blood pressure [14]. Ten-year risk in percentage was also calculated. Subjects with SCORE $<1 \%$ were included in the category of low risk. Those with a SCORE $\geq 1 \%$ and $<5 \%$ were in the category of moderate risk. When the SCORE chart result was $\geq 5 \%$ and $<10 \%$ they were classified as having high risk. Finally, those patients with SCORE results $\geq 10 \%$ were included in the category of very high CV risk. Based on European guidelines [2], subjects with a documented history of stroke, transient ischemic attack, or CHD were classified as very high-risk individuals, regardless of SCORE percentage; likewise, subjects with a markedly elevated single risk factors (total cholesterol [TC] $>310 \mathrm{mg} / \mathrm{dL}$, LDLC $>190 \mathrm{mg} / \mathrm{dL}$, or BP $\geq 180 / 110$ ) or with a documented history of diabetes were classified as high-risk individuals.

Continuous variables were tested for normality using the Kolmogorov-Smirnov test. Data are presented as medians and 25th and 75th percentiles for continuous variables with a non-normal distribution or means and standard deviations (SD) for variables with a normal distribution. Categorical variables are reported as counts and percentages. Differences between cohorts were analysed using the non-parametric Mann-Whitney test or Student's parametric $t$-test for continuous variables and the chi-square test or Fisher's exact test for categorical variables.

All analyses were performed using Statistical Analysis System software, version 9.4 (Statistical Analysis System Institute, Inc, Cary, $\mathrm{NC}$ ). Statistical significance was set at the 0.05 level for every analysis performed. 


\section{Results}

A total of 609 individuals (mean [SD] age 55 [8] years, about 39\% males) for each cohort were selected. Demographics and basic characteristics of subjects belonging to PLIC and ESSE-RF samples are presented in Table 1. ESSE-RF cohort was characterized by higher mean values of body mass index $\left(28.36 \mathrm{vs} 26.46 \mathrm{~kg} / \mathrm{m}^{2}\right.$, pvalue<.0001), systolic BP $(134.35$ vs $125.00 \mathrm{~mm} \mathrm{Hg}$, pvalue $<.0001)$, diastolic $\mathrm{BP}(82.01$ vs $78.35 \mathrm{~mm} \mathrm{Hg}$, p-value $<.0001)$, TC (215.65 vs $209.33 \mathrm{mg} / \mathrm{dL}$, p-value $=.01)$, LDL-C (138.44 vs $126.80 \mathrm{mg} / \mathrm{dL}$, p-value<.0001), non-HDL (164.44 vs $147.25 \mathrm{mg} / \mathrm{dL}$, p-value<.0001), TG (median 108.06 vs $90.00 \mathrm{mg} / \mathrm{dL}$, pvalue $<.0001$ ), and intima-media thickness (IMT, left measurement 0.81 vs $0.70 \mathrm{~mm}$ p-value $<.0001$, right measurement 0.80 vs $0.69 \mathrm{~mm}$ p-value $<.0001$ ), and lower mean values of HDL ( $51.29 \mathrm{vs}$ $62.07 \mathrm{mg} / \mathrm{dL}, \mathrm{p}$-value<.0001) and ankle-brachial index (ABI, left measurement 1.09 vs $1.17 \mathrm{p}$-value $<.0001$, right measurement 1.08 vs $1.15 \mathrm{p}$-value<.0001), compared to PLIC sample distributions. Significant differences were also observed in the prevalence of traditional cardiovascular risk factors: the percentage of smokers, participants with increased IMT (>0.9 mm; $26 \%$ vs $15 \%$ ), LDL-C (>150 mg/dL; 38\% vs 23\%, >190 mg/dL; $9 \%$ vs 3\%), TG (>150 mg/ dL; $13 \%$ vs $28 \%$ ), and non-HDL (>180 mg/dL; 33\% vs $17 \%,>220 \mathrm{mg} /$
dL; $10 \%$ vs $2 \%$ ) were higher in ESSE-RF cohort, while the percentage of subjects with decreased $A B I$ index $(\leq 0.9 ; 13 \%$ vs $5 \%)$ was higher in PLIC cohort. Overall, individuals belonging to ESSE-RF sample showed a more severe profile regarding the prevalence of CHD, hypertension and diabetes.

Based on European guidelines (as reported in the methods section), almost half of PLIC cohort participants belonged to the moderate risk group (47\% vs $27 \%$, Fig. 1), while in ESSE-RF cohort a relatively higher prevalence of individuals classified in the high and very high risk group was observed ( $19 \%$ vs $11 \%, 21 \%$ vs $6 \%$, respectively).

In particular, about $37 \%(\mathrm{~N}=223)$ of the ESSE-RF cohort and $13 \%$ $(\mathrm{N}=77$ ) of PLIC cohort participants ( $\mathrm{p}$-value for difference in prevalence $<.0001$ ) were allocated in the high/very high $\mathrm{CV}$ risk groups, regardless of SCORE percentage, due to the presence of a documented atherosclerotic cardiovascular disease (ASCVD), prevalence of diabetes, as well as values of TC, LDL-C, and BP above the cut-off points above mentioned (Table 2).

Instead, the analysis of determinants characterizing SCORE chart, showed a higher prevalence of smokers in any $\mathrm{CV}$ risk class in the ESSE-RF cohort compared to PLIC subjects, as well as a higher prevalence of SBP> $140 \mathrm{~mm} \mathrm{Hg}$ (38\% vs $11 \%$ ) evaluating individuals belonging to the moderate $\mathrm{CV}$ risk group (prevalence becomes

Table 1

Demographics and characteristics of subjects belonging to PLIC and ESSE-RF samples matched by age and sex.

\begin{tabular}{|c|c|c|c|c|c|}
\hline & \multicolumn{2}{|c|}{ Milan } & \multicolumn{2}{|c|}{ St Petersburg } & \multirow[t]{2}{*}{ p-value } \\
\hline & $\mathrm{N}$ & Mean (SD) & $\mathrm{N}$ & Mean (SD) & \\
\hline Age, years & 609 & $56.0(8.8)$ & 609 & $54.7(8.4)$ & 0.24 \\
\hline BMI, $\mathrm{kg} / \mathrm{m}^{2}$ & 606 & $26.46(4.32)$ & 609 & $28.36(4.96)$ & $<.0001$ \\
\hline SBP, mm Hg & 605 & $125(15.4)$ & 608 & $134.35(21.4)$ & $<.0001$ \\
\hline DBP, mm Hg & 605 & $78.35(9.3)$ & 608 & $82.01(12.02)$ & $<.0001$ \\
\hline $\mathrm{TC}, \mathrm{mg} / \mathrm{dL}$ & 609 & $209.33(36.18)$ & 603 & $215.65(43.91)$ & 0.01 \\
\hline $\mathrm{HDL}, \mathrm{mg} / \mathrm{dL}$ & 609 & $62.07(17.19)$ & 606 & $51.29(13.29)$ & $<.0001$ \\
\hline non-HDL, mg/dL & 609 & $147.25(36.74)$ & 603 & $164.44(40.85)$ & $<.0001$ \\
\hline $\mathrm{LDL}, \mathrm{mg} / \mathrm{dL}$ & 609 & $126.8(32.67)$ & 606 & $138.44(38.02)$ & $<.0001$ \\
\hline $\mathrm{TG}, \mathrm{mg} / \mathrm{dL}$ & 609 & $90[66-124]$ & 606 & 108.06 [81.48-155] & $<.0001$ \\
\hline Glucose, mg/dL & 609 & $92.31(14.4)$ & 606 & $95.25(21.01)$ & 0.03 \\
\hline Creatinine, mg/dL & 609 & $0.84(0.35)$ & 606 & $0.76(0.14)$ & $<.0001$ \\
\hline Clearance CG & 606 & $93.19(22.91)$ & 605 & $97.64(10.75)$ & $<.0001$ \\
\hline IMT right, mm & 604 & $0.69(0.16)$ & 417 & $0.80(0.17)$ & $<.0001$ \\
\hline IMT left, mm & 604 & $0.70(0.17)$ & 417 & $0.81(0.17)$ & $<.0001$ \\
\hline $\mathrm{ABI}$ right & 501 & $1.15(0.18)$ & 454 & $1.08(0.1)$ & $<.0001$ \\
\hline \multirow[t]{2}{*}{ ABI left } & 401 & $1.17(0.2)$ & 456 & $1.09(0.1)$ & $<.0001$ \\
\hline & $\mathbf{N}$ & $\%$ & $\mathbf{N}$ & $\%$ & p-value \\
\hline Male & 235 & 38.6 & 235 & 38.6 & 1.0 \\
\hline Smoker & 108 & 17.7 & 140 & 23.0 & 0.004 \\
\hline $\mathrm{TC}>190 \mathrm{mg} / \mathrm{dL}$ & 424 & 69.62 & 432 & 71.64 & 0.44 \\
\hline $\mathrm{TG}>150 \mathrm{mg} / \mathrm{dL}$ & 82 & 13.46 & 167 & 27.56 & $<.0001$ \\
\hline $\mathrm{HDL}<40 / 50(\mathrm{M} / \mathrm{F}) \mathrm{mg} / \mathrm{dL}$ & 49 & 8.05 & 170 & 28.05 & $<.0001$ \\
\hline non-HDL $>145 \mathrm{mg} / \mathrm{dL}$ & 308 & 50.57 & 406 & 67.33 & $<.0001$ \\
\hline non-HDL> $180 \mathrm{mg} / \mathrm{dL}$ & 106 & 17.41 & 200 & 33.17 & $<.0001$ \\
\hline non-HDL>220 mg/dL & 15 & 2.46 & 59 & 9.78 & $<.0001$ \\
\hline $\mathrm{LDL}>115 \mathrm{mg} / \mathrm{dL}$ & 375 & 61.58 & 446 & 73.6 & $<.0001$ \\
\hline $\mathrm{LDL}>150 \mathrm{mg} / \mathrm{dL}$ & 141 & 23.15 & 228 & 37.62 & $<.0001$ \\
\hline $\mathrm{LDL}>190 \mathrm{mg} / \mathrm{dL}$ & 17 & 2.79 & 54 & 8.91 & $<.0001$ \\
\hline \multicolumn{6}{|l|}{ Subclinical vascular damage } \\
\hline $\mathrm{ABI} \leq 0.9$ & 51 & 12.88 & 23 & 5.07 & $<.0001$ \\
\hline $\mathrm{IMT}>0.9 \mathrm{~mm}$ & 85 & 14.97 & 110 & 26.38 & $<.0001$ \\
\hline \multicolumn{6}{|l|}{ Diseases and treatments } \\
\hline CHD & 18 & 3.0 & 117 & 21.3 & $<.0001$ \\
\hline Stroke + TIA & 16 & 2.6 & 14 & 2.6 & 0.96 \\
\hline Hypertension & 272 & 44.66 & 406 & 66.67 & $<.0001$ \\
\hline Diabetes & 27 & 4.43 & 70 & 11.49 & $<.0001$ \\
\hline Hypertension trt & 178 & 29.23 & 227 & 37.27 & 0.003 \\
\hline Diabetes trt & 17 & 2.79 & 40 & 6.59 & 0.002 \\
\hline Lipid-lowering trt & 158 & 25.94 & 49 & 8.14 & $<.0001$ \\
\hline
\end{tabular}

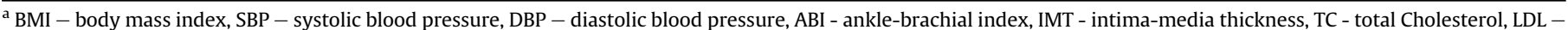

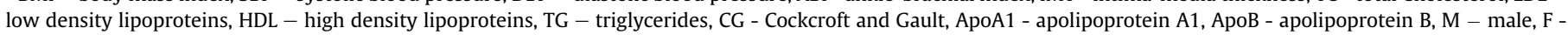
female, CHD - coronary heart disease, TIA - transient ischemic attack, trt - treatment. 


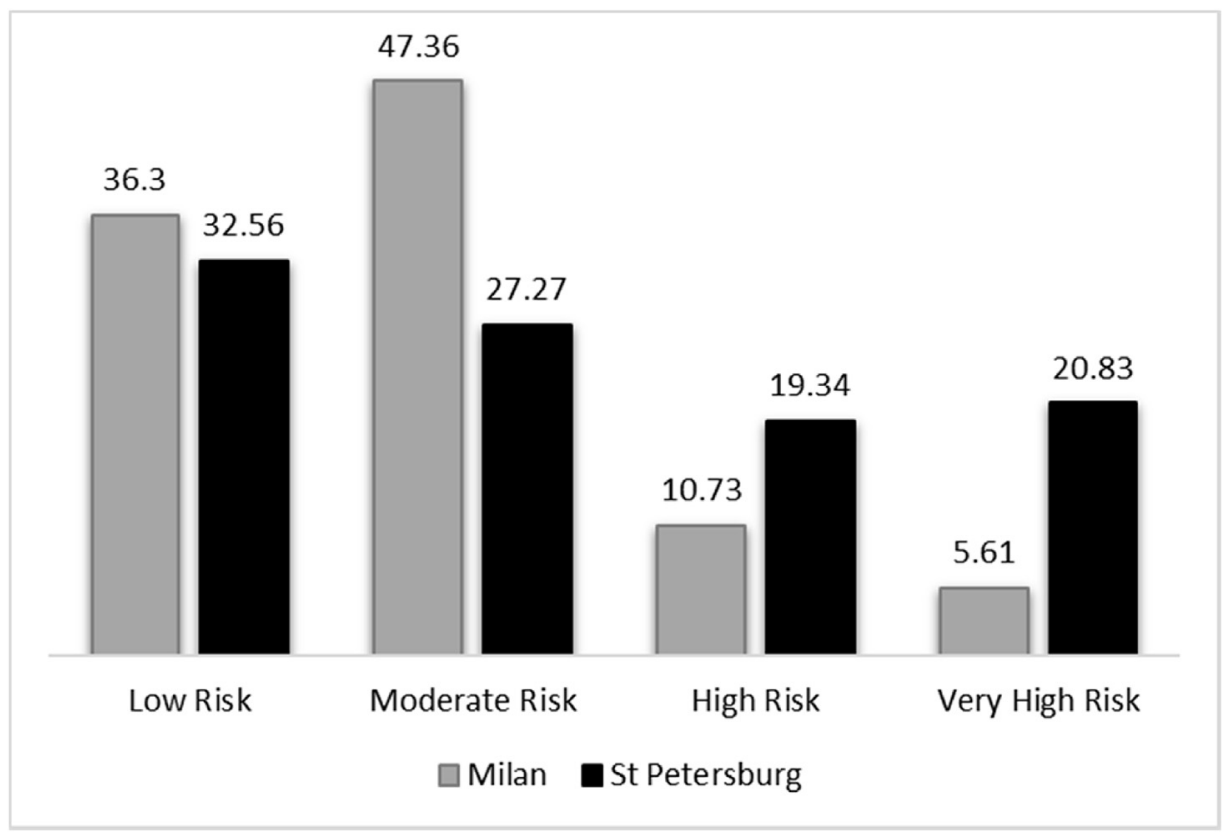

Fig. 1. Distribution (\%) of CV risk stratification of patients included in PLIC and ESSE-RF-RF samples.

Table 2

Distribution of components that automatically classify patients as a high/very high CV risk - pre-SCORE evaluation.

\begin{tabular}{lllllll}
\hline & \multicolumn{2}{l}{ Milan } & & \multicolumn{2}{l}{ St Petersburg } & \multirow{2}{*}{ p-value } \\
\cline { 2 - 3 } & $\mathrm{N}$ & $\%$ & & $\mathrm{~N}$ & $\%$ & \\
\hline Documented ASCVD & 33 & 5.42 & & 125 & 20.53 & $<.0001$ \\
$\mathrm{TC}>310 \mathrm{mg} / \mathrm{dL}$ & 4 & 0.66 & & 13 & 2.13 & 0.03 \\
$\mathrm{LDL}>190 \mathrm{mg} / \mathrm{dL}$ & 17 & 2.79 & & 52 & 8.54 & $<.0001$ \\
$\mathrm{BP} \geq 180 / 110 \mathrm{~mm} \mathrm{Hg}$ & 4 & 0.66 & & 33 & 5.42 & $<.0001$ \\
Diabetes & 27 & 4.43 & & 70 & 11.49 & $<.0001$ \\
\hline
\end{tabular}

${ }^{a}$ Documented ASCVD - included self-reported history of stroke, transient ischemic attack, coronary heart disease, acute myocardial infarction, angina, silent ischemia, or percutaneous transluminal coronary angiography, TC - total Cholesterol, LDL low density lipoproteins, BP - blood pressure.

higher in PLIC cohort considering the high risk class). On the other hand, a TC $>190 \mathrm{mg} / \mathrm{dL}$ was detected more often in all the CV risk categories of PLIC sample, but more participants with TC $>230 \mathrm{mg} /$ $\mathrm{dL}$ in moderate (39\% vs $27 \%$ ) and high risk (26\% vs $20 \%$ ) groups of ESSE-RF cohort were observed (Table 3).

Table 4 reports the distribution of MetS determinants among different sub-populations. ESSE-RF sample was characterized by higher prevalence of $S B P / D B P \geq 130 / 85 \mathrm{~mm} \mathrm{Hg}$ (66\% vs 56\%, pvalue $=.001)$, glucose $\geq 100 \mathrm{mg} / \mathrm{dL}(28 \%$ vs $22 \%$, p-value $=.01)$, TG $\geq 150 \mathrm{mg} / \mathrm{dL}(28 \%$ vs $20 \%$, p-value $=.001), \mathrm{HDL}<40 / 50(\mathrm{M} / \mathrm{F})$ $\mathrm{mg} / \mathrm{dL}$ (39\% vs $19 \%$, p-value $<.0001$ ), and waist $\geq 102 / 88(\mathrm{M} / \mathrm{F}) \mathrm{cm}$ ( $50 \%$ vs $38 \%$, p-value $<.0001$ ), leading to a $43 \%$ of participants with MetS (using $94 / 80$ as cut-off for waist circumference) among this cohort, compared with the $27 \%$ of PLIC members (the difference in prevalence becomes $37 \%$ vs $21 \%$, considering $102 / 88$ as cut-off). Considering only subjects with MetS (Table 4, panel C and D), determinants that have a greater impact on the diagnosis of the syndrome are waist circumference and BP, in both cohorts. Indeed, about $91 \%$ and $85 \%$ of PLIC subjects, and $96 \%$ and $93 \%$ of ESSE-RF individuals with MetS, reported a waist circumference $\geq 94 / 80$ (M/ $\mathrm{F}) \mathrm{cm}$ and a $\mathrm{SBP} / \mathrm{DBP} \geq 130 / 85 \mathrm{~mm} \mathrm{Hg}$, respectively (percentages become $74 \%, 88 \%, 84 \%$, and $94 \%$ using $102 / 88$ as cut-off for waist [MetS group 2]). Instead, if in the PLIC cohort both glucose $\geq 100 \mathrm{mg} / \mathrm{dL}$ and TG $\geq 150 \mathrm{mg} / \mathrm{dL}$ have a similar impact on
MetS diagnosis (regardless of which waist threshold is applied), in the ESSE-RF sample the prevalence of subjects reporting a $\mathrm{HDL}<40$ / $50(\mathrm{M} / \mathrm{F}) \mathrm{mg} / \mathrm{dL}$ is much higher (about $66 \%$ vs $55 \%$ in the PLIC cohort, or $67 \%$ vs $62 \%$ considering MetS group 2), suggesting that this factor seems to play a more important role as third determinant for the diagnosis of MetS, especially when a less conservative cut-off for waist circumference is used.

Fig. 2 (using 94/80 cm as cut-off for waist circumference) and Fig. 3 (using 102/88 cm as cut-off for waist circumference) present the association between the number of metabolic syndrome components and SCORE categories (due to the very low number of subjects belonging to the very high CV risk category, a combined category of subjects at high/very high CV risk is presented) among PLIC (panel A) and ESSE-RF (panel B) participants. As shown in Fig. 2, the highest prevalence of patients with one or two risk factors for metabolic syndrome were in the low and moderate CV risk groups, and especially the latter is also characterized by a high prevalence of patients with three determinants, while patients with four or five risk factors for MetS were most prevalent in individuals at high/very high CV risk, in both cohorts, but with a more defined trend towards the increase of MetS components moving from the lowest to the highest CV risk class in the ESSE-RF sample, probably because not many PLIC subjects were at high/very high CV risk. The same considerations are worth done when $102 / 88 \mathrm{~cm}$ cutoff for waist circumference is used as MetS determinant (Fig. 3).

\section{Discussion}

Based on epidemiological update on CVD in Europe, estimated disability-adjusted life years (being the equivalent to 1 year of healthy life lost) for CVD per 1000 subjects is 54 for Italy and 181 for Russia [15]. This emphasizes not only that, despite all the remarkable and unprecedented progress in addressing CVD, this disease remains a massive burden for national healthcare systems globally, but also that strategies that need to be implemented for CV risk decrease in the next 5-10 years should be based on the current situation and on CV risk particularities, on a country-based level.

In this study, categorization of subjects in different $\mathrm{CV}$ risk 
Table 3

Distribution of determinants characterizing SCORE chart.

\begin{tabular}{|c|c|c|c|c|c|c|c|c|}
\hline & \multicolumn{2}{|l|}{ Low Risk } & \multicolumn{2}{|c|}{ Moderate Risk } & \multicolumn{2}{|l|}{ High Risk } & \multicolumn{2}{|c|}{ Very High Risk } \\
\hline & Milan & St Petersburg & Milan & St Petersburg & Milan & St Petersburg & Milan & St Petersburg \\
\hline Age, mean (SD) & $48.6(8.3)$ & $46.8(8.2)$ & $60.6(4.9)$ & $58.3(4.7)$ & $63.4(3.1)$ & $61.3(2.2)$ & 63 n.a. & 60 n.a. \\
\hline $\begin{array}{l}\text { Men, } \\
\text { N (\%) }\end{array}$ & $51(23.2)$ & $51(25.9)$ & $128(44.6)$ & $85(51.5)$ & $19(90.5)$ & $18(94.7)$ & $1(100.0)$ & $1(100.0)$ \\
\hline $\begin{array}{l}\text { Smoker, } \\
\mathrm{N}(\%)\end{array}$ & $26(11.8)$ & $29(14.7)$ & $59(20.6)$ & $51(30.9)$ & $8(38.1)$ & $15(79.0)$ & $1(100.0)$ & $1(100.0)$ \\
\hline $\mathrm{SBP}>120 \mathrm{~mm} \mathrm{Hg}, \mathrm{N}(\%)$ & $57(25.9)$ & $91(46.2)$ & $163(56.8)$ & $132(80.0)$ & $21(100.0)$ & $19(100.0)$ & $1(100.0)$ & $1(100.0)$ \\
\hline $\mathrm{SBP}>140 \mathrm{~mm} \mathrm{Hg}, \mathrm{N}(\%)$ & $4(1.8)$ & $23(11.7)$ & $31(10.8)$ & $62(37.6)$ & $15(71.4)$ & $11(57.99)$ & $1(100.0)$ & $1(100.0)$ \\
\hline $\mathrm{SBP}>160 \mathrm{~mm} \mathrm{Hg}, \mathrm{N}(\%)$ & $0(0.0)$ & $1(0.5)$ & $1(0.4)$ & $8(4.9)$ & $2(9.5)$ & $2(10.5)$ & $0(0.0)$ & $1(100.0)$ \\
\hline $\begin{array}{l}\mathrm{TC}>190 \mathrm{mg} / \mathrm{dL} \\
\mathrm{N}(\%)\end{array}$ & $154(70.0)$ & $123(62.4)$ & $201(70.0)$ & $122(73.9)$ & $18(85.7)$ & $13(68.4)$ & $0(0.0)$ & $1(100.0)$ \\
\hline $\begin{array}{l}\mathrm{TC}>230 \mathrm{mg} / \mathrm{dL}, \\
\mathrm{N}(\%)\end{array}$ & $54(24.6)$ & $41(20.8)$ & $77(26.8)$ & $65(39.4)$ & $4(19.5)$ & $5(26.3)$ & $0(0.0)$ & $0(0.0)$ \\
\hline $\begin{array}{l}\mathrm{TC}>270 \mathrm{mg} / \mathrm{dL}, \\
\mathrm{N}(\%)\end{array}$ & $1(0.5)$ & $7(3.6)$ & $5(1.7)$ & $10(6.1)$ & $0(0.0)$ & $0(0.0)$ & $0(0.0)$ & $0(0.0)$ \\
\hline
\end{tabular}

${ }^{\mathrm{a}}$ SBP - systolic blood pressure, TC - total Cholesterol, n.a. - not applicable.

Table 4

Distribution of determinants characterizing metabolic syndrome (N, and \%) in ESSERF and PLIC matched samples (panel A), in subjects belonging to MetS group 1 (metabolic syndrome calculated using $94 / 80$ as cut-off for waist circumference, panel B), and to MetS group 2 (metabolic syndrome calculated using 102/88 as cutoff for waist circumference, panel C).

\begin{tabular}{|c|c|c|c|c|c|}
\hline & \multicolumn{2}{|c|}{ Milan } & \multicolumn{2}{|c|}{ St Petersburg } & \multirow[t]{2}{*}{ p-value } \\
\hline & $\mathrm{N}$ & $\%$ & $\mathrm{~N}$ & $\%$ & \\
\hline \multicolumn{6}{|l|}{ A } \\
\hline Waist $\geq 94 / 80(M / F) \mathrm{cm}$ & 405 & 67.05 & 436 & 71.95 & 0.06 \\
\hline Waist $\geq 102 / 88(\mathrm{M} / \mathrm{F}) \mathrm{cm}$ & 228 & 37.75 & 305 & 50.33 & $<.0001$ \\
\hline $\mathrm{SBP} / \mathrm{DBP} \geq 130 / 85 \mathrm{~mm} \mathrm{Hg}$ & 342 & 56.16 & 401 & 65.85 & 0.001 \\
\hline Glucose $\geq 100 \mathrm{mg} / \mathrm{dL}$ & 132 & 21.67 & 169 & 27.75 & 0.01 \\
\hline $\mathrm{TG} \geq 150 \mathrm{mg} / \mathrm{dL}$ & 120 & 19.7 & 167 & 27.56 & 0.001 \\
\hline $\mathrm{HDL}<40 / 50(\mathrm{M} / \mathrm{F}) \mathrm{mg} / \mathrm{dL}$ & 116 & 19.05 & 238 & 39.27 & $<.0001$ \\
\hline MetS group 1 & 164 & 27.0 & 259 & 42.7 & $<.0001$ \\
\hline MetS group 2 & 130 & 21.4 & 226 & 37.3 & $<.0001$ \\
\hline \multicolumn{6}{|l|}{ B } \\
\hline Waist $\geq 94 / 80(\mathrm{M} / \mathrm{F}) \mathrm{cm}$ & 147 & 90.74 & 247 & 95.74 & 0.04 \\
\hline $\mathrm{SBP} / \mathrm{DBP} \geq 130 / 85 \mathrm{~mm} \mathrm{Hg}$ & 139 & 84.76 & 242 & 93.44 & 0.004 \\
\hline Glucose $\geq 100 \mathrm{mg} / \mathrm{dL}$ & 99 & 60.37 & 135 & 52.12 & 0.10 \\
\hline $\mathrm{TG} \geq 150 \mathrm{mg} / \mathrm{dL}$ & 99 & 60.37 & 138 & 53.28 & 0.15 \\
\hline $\begin{array}{l}\mathrm{HDL}<40 / 50(\mathrm{M} / \mathrm{F}) \mathrm{mg} / \mathrm{dL} \\
\text { C }\end{array}$ & 91 & 55.49 & 171 & 66.02 & 0.03 \\
\hline Waist $\geq 102 / 88(M / F) \mathrm{cm}$ & 95 & 74.22 & 190 & 84.44 & 0.02 \\
\hline $\mathrm{SBP} / \mathrm{DBP} \geq 130 / 85 \mathrm{~mm} \mathrm{Hg}$ & 115 & 88.46 & 212 & 93.81 & 0.08 \\
\hline Glucose $\geq 100 \mathrm{mg} / \mathrm{dL}$ & 82 & 63.08 & 131 & 57.96 & 0.15 \\
\hline $\mathrm{TG} \geq 150 \mathrm{mg} / \mathrm{dL}$ & 82 & 63.08 & 131 & 57.96 & 0.34 \\
\hline $\mathrm{HDL}<40 / 50(\mathrm{M} / \mathrm{F}) \mathrm{mg} / \mathrm{dL}$ & 81 & 62.31 & 152 & 67.26 & 0.34 \\
\hline
\end{tabular}

a SBP - systolic blood pressure, DBP - diastolic blood pressure, HDL - high density lipoproteins, TG - triglycerides, M - male (median and IQR are reported in the table), $\mathrm{F}$ - female, MetS group 1 - metabolic syndrome calculated using 94/80 as cutoff for waist circumference, MetS group 2 - metabolic syndrome calculated using $102 / 88$ as cut-off for waist circumference.

groups based on SCORE assessment revealed that $47 \%$ of the PLIC cohort belong to the moderate CV risk class (vs 27\% of ESSE-RF members), while in ESSE-RF cohort $40 \%$ of participants are at high and very high CV risk (vs 16\% of PLIC members). Distribution of determinants characterizing SCORE chart showed a higher prevalence of moderate BP and TC in PLIC cohort, and a higher prevalence of patients with severe increase of BP and TC in ESSE-RF cohort, which may indicate a worse control of CV risk factors in the latter cohort. Moreover, within the structure of high and very high risk groups, only $5.4 \%$ of patients in PLIC cohort had documented ASCVD (i.e. could be interpreted as a secondary prevention zone), vs $20.5 \%$ pf individuals in ESSE-RF cohort. These findings are in accordance with results of previous studies. Results published in 2016 based on population data of 12 representative regions of Russian Federation, revealed that $31,3 \%$ of patients belonged to high and very high
SCORE CV risk, $34.7 \%$ to the moderate CV risk class and $26.8 \%$ to the low CV risk group [10]. In another study, where 7000 Italian subjects aged between 49 and 70 years were enrolled, $15.1 \%$ of individuals were in high risk of CVD, and $19.9 \%$ had very high CV risk, based on the CUORE Project algorithm that predicts 10-year probability of developing a first major CV event [16].

Based on data about CV risk features distribution, a question of slightly different efforts and counselling in prevention strategies might be argued. In countries with a relatively higher prevalence of subjects at high/very high CV risk, especially if they are in secondary prevention, intensification and organization of new specialized CV centres, including high-tech medical care, might be considered. In countries where the CV mortality line went down during last decades and the overwhelming majority of the population belongs to the low and moderate CV risk classes, populationbased approaches might be more cost-effective for making another step in CV risk reduction as even rare CV events that come from low and moderate risk groups bring a tangible burden to healthcare systems if a high number of subjects are classified as non-high risk individuals.

In this study, the distribution of MetS determinants among two sub-populations revealed higher prevalence of $S B P / D B P \geq 130 /$ $85 \mathrm{~mm} \mathrm{Hg}$, glucose $\geq 100 \mathrm{mg} / \mathrm{dL}, \mathrm{TG} \geq 150 \mathrm{mg} / \mathrm{dL}, \mathrm{HDL}<40 / 50(\mathrm{M} / \mathrm{F})$ $\mathrm{mg} / \mathrm{dL}$ and waist $\geq 102 / 88(\mathrm{M} / \mathrm{F}) \mathrm{cm}$ in ESSE-RF cohort, leading to a $43 \%$ of participants with MetS (using 94/80 as cut-off for waist circumference), compared with the $27 \%$ of PLIC members. Key determinants based on their impact on MetS diagnosis in both populations are waist circumference and BP. In a meta-analysis of 21 studies published in 2017 aiming at assessing the association of MetS with carotid atherosclerosis, showed that among 34,635 subject, 22,9\% of them received a diagnosis of MetS [17]; a prevalence very close to what we found in our study for the PLIC cohort. Results of an Italian population study with a total of 2100 subjects (mean [SD] age 55.5 [14.6] years, 45\% males) showed that MetS was more common in women than in men (18\% vs $15 \%$ ), and that its prevalence increased from $3 \%$ among subjects aged between 20 and 29 years to $25 \%$ in subjects aged 70 years or older [18]. However, another Italian study done within 3 regions by using of GPs clinical databases demonstrated relatively relevant to PLIC study prevalence: 34.9\% - in Regione Lazio, 33.2\% - in Regione Piemonte, and $31.9 \%$ - in Regione Umbria [19]. Obviously, higher prevalence of MetS among ESSE-RF subjects dictates the necessity to enforce efforts in MetS components management.

In our study, a logical trend through an increase number of MetS determinants moving from the lowest to the highest $\mathrm{CV}$ risk groups was observed, and more generally, the number of metabolic 

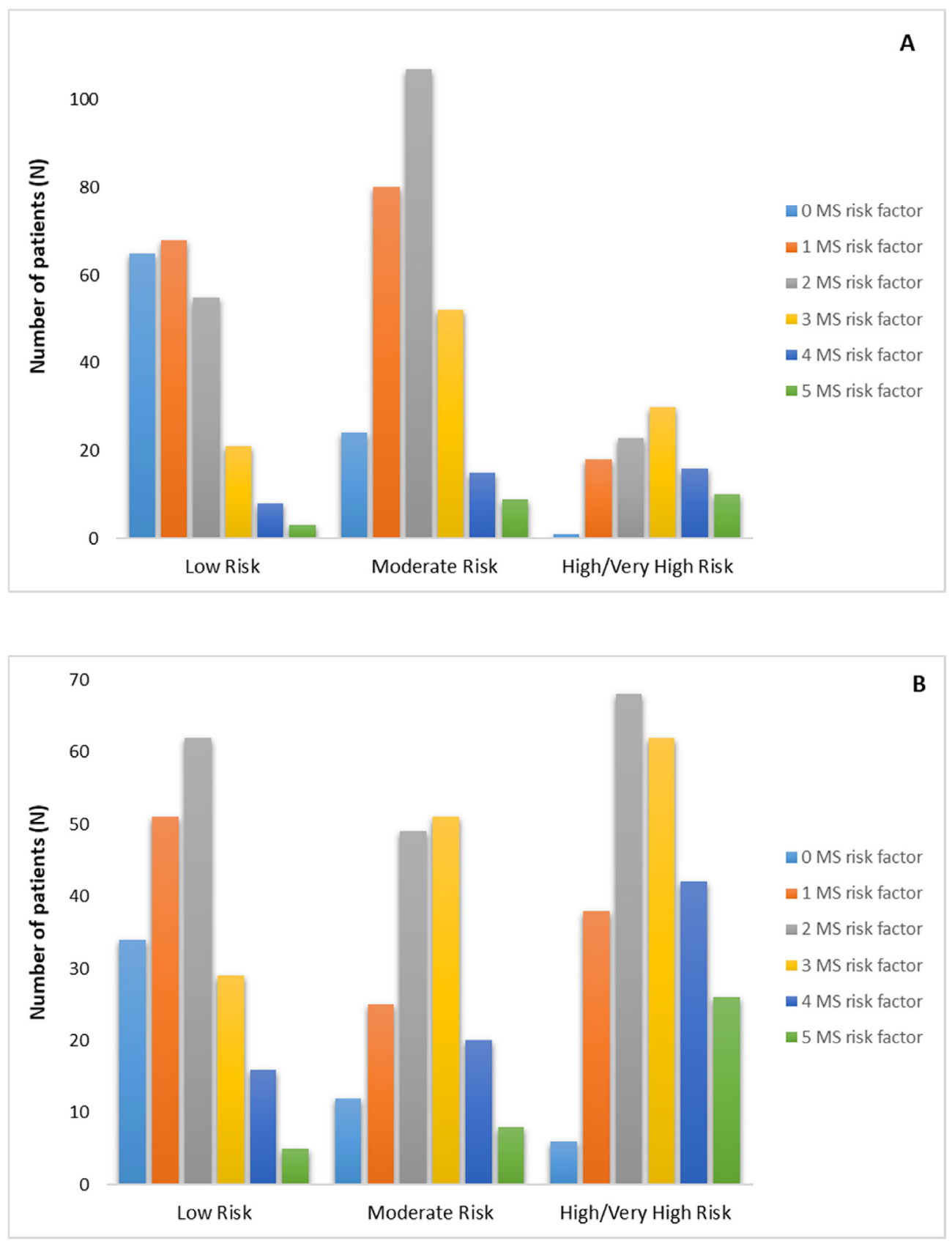

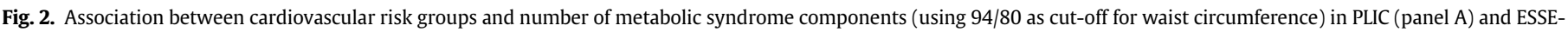
RF (panel B) samples.

syndrome components in patients of high/very high risk score was significantly higher than the other groups. The analysis confirms that a population characterized by higher CV risk showed also a higher prevalence of metabolic dysfunction, but, more importantly, that also low/moderate $\mathrm{CV}$ risk patients are in part characterized by MetS ( $14.5 \%$ and $25.5 \%$ in the PLIC cohort and $22.3 \%$ and $41.8 \%$ in the ESSE-RF cohort, respectively), highlighting the possibility to further stratify these groups and (based on the assumption of a correlation between MetS and CV risk) prioritize prevention strategies. Otherwise, this hypothesis can also work the other way around. The study by Takahashi et al. [20], reported a positive correlation between CAD risk score and the number of metabolic syndrome components: the greater the metabolic syndrome components, the higher the risk of developing CAD. Unluckily, the cross-sectional nature of the current study makes it difficult to better address the direction of this relationship.

\section{Conclusion}

This cross-sectional study raises the question of designing countries-based personalized prevention strategies, based on the relatively different distribution of $\mathrm{CV}$ risk factors and $\mathrm{CV}$ risk groups correspondence. Strategical approaches in CV risk management on a population level might bring more effectiveness if they are implemented based on these aspects. 

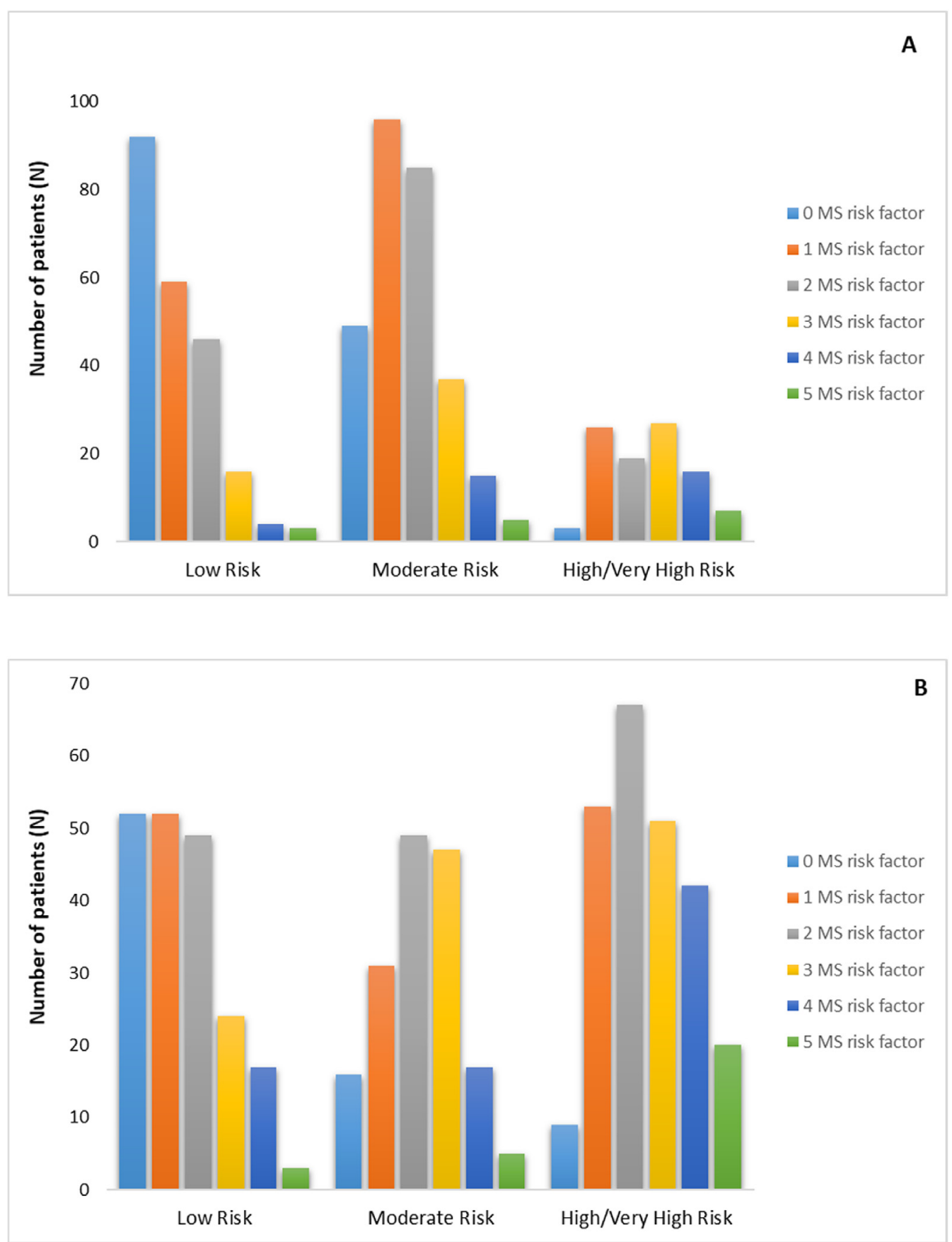

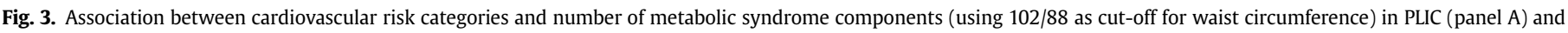
ESSE-RF (panel B) samples.

\section{CRediT authorship contribution statement}

Asiiat S. Alieva: Conceptualization, Writing - original draft, responsible for the study concept and design, contributed to the interpretation of the results, wrote the manuscript, all authors critically revised for important intellectual content and approved the final manuscript. Elena Olmastroni: Conceptualization, Formal analysis, Writing - original draft, responsible for the study concept and design, did the analysis, contributed to the interpretation of the results, wrote the manuscript, all authors critically revised for important intellectual content and approved the final manuscript., all authors critically revised for important intellectual content and approved the final manuscript. Olga V. Reutova: Data curation,
Writing - original draft, responsible for literature search, study selection, and data collection, contributed to the interpretation of the results, wrote the manuscript, all authors critically revised for important intellectual content and approved the final manuscript. Oxana P. Rotar: Data curation, responsible for literature search, study selection, and data collection, contributed to the interpretation of the results, all authors critically revised for important intellectual content and approved the final manuscript. Alexandra $\mathbf{0}$. Konradi: Conceptualization, responsible for the study concept and design, contributed to the interpretation of the results, all authors critically revised for important intellectual content and approved the final manuscript. Evgeny V. Shlyakhto: Conceptualization, responsible for the study concept and design, all authors critically 
revised for important intellectual content and approved the final manuscript. Andrea Baragetti: Data curation, responsible for literature search, study selection, and data collection, contributed to the interpretation of the results, all authors critically revised for important intellectual content and approved the final manuscript. Liliana Grigore: Data curation, responsible for literature search, study selection, and data collection, all authors critically revised for important intellectual content and approved the final manuscript. Fabio Pellegatta: Data curation, responsible for literature search, study selection, and data collection, all authors critically revised for important intellectual content and approved the final manuscript., all authors critically revised for important intellectual content and approved the final manuscript. Manuela Casula: Data curation, responsible for literature search, study selection, and data collection, contributed to the interpretation of the results, all authors critically revised for important intellectual content and approved the final manuscript. Elena Tragni: Data curation, responsible for literature search, study selection, and data collection, contributed to the interpretation of the results, all authors critically revised for important intellectual content and approved the final manuscript. Alberico L. Catapano: Conceptualization, responsible for the study concept and design, contributed to the interpretation of the results, all authors critically revised for important intellectual content and approved the final manuscript.

\section{Declaration of competing interest}

All authors declare no support from any organization for the submitted work; no other relationships or activities that could appear to have influenced the submitted work. EO, AB, LG, FP, ET, MC, OVR report no disclosures. ALC reports grants from Amgen, Sanofi, Regeneron personal fees from Merck, Sanofi, Regeneron, AstraZeneca, Amgen, Novartis, outside the submitted work AA received research funding and/or honoraria for speaker bureau from Abbott, Amgen, KRKA, Pfizer, Recordati, Sanofi-Regeneron, Servier. OPR received research funding and/or honoraria for speaker bureau from KRKA, Pfizer, Recordati, Sanofi-Regeneron, Servier, Stada, Teva, Sandoz. AK received research funding and/or honoraria for speaker bureau from Servier, Novartis.

\section{Acknowledgments}

The authors received no financial support for the research, authorship, and/or publication of this article. The work of ALC is supported by Ministry of Health - Ricerca Corrente - IRCCS MultiMedica, PRIN 2017H5F943 and ERANET ER-2017-2364981 The Russian part of the project was supported by the Russian Science Foundation under Grant number 17-15-01177. The PLIC study (Progression of Lesions in the Intima of the Carotid) is supported, in part, by the following grants: the European Union Framework Programmes for Research and Innovation Horizon 2020-Personalising Health and Care (H2020 REPROGRAM PHC03-2015/667837-2 and ERA-NET ER-2017-2364981). We acknowledge Laura Redaelli and Cristina Tidone for their contribution to data collection in the progression of lesions in the intima of the carotid (PLIC) study. This article is part of a Supplement entitled "Plasma lipids and cardiovascular risk: Nutritional and therapeutic approaches" published with support from Società Italiana di Terapia Clinica e Sperimentale (SITeCS).

\section{References}

[1] Lozano R, Naghavi M, Foreman K, Lim S, Shibuya K, et al. Global and regional mortality from 235 causes of death for 20 age groups in 1990 and 2010: a systematic analysis for the Global Burden of Disease Study 2010. Lancet 2012;380(9859):2095-128. https://doi.org/10.1016/S0140-6736(12)61728-0.

[2] Piepoli MF, Hoes AW, Agewall S, Albus C, Brotons C, et al. 2016 European guidelines on cardiovascular disease prevention in clinical practice: the sixth joint task force of the European society of cardiology and other societies on cardiovascular disease prevention in clinical practice (constituted by representatives of 10 societies and by invited experts) developed with the special contribution of the European association for cardiovascular prevention \& rehabilitation (EACPR). Eur Heart J 2016;37(29):2315-81. https://doi.org/ 10.1093/eurheartj/ehw106.

[3] Williams B, Mancia G, Spiering W, Rosei EA, Azizi M, et al. 2018 ESC/ESH guidelines for the management of arterial hypertension: the task force for the management of arterial hypertension of the European society of cardiology (ESC) and the European society of hypertension (ESH). Eur Heart J 2018;39(33):3021-104. https://doi.org/10.1093/eurheartj/ehy339.

[4] Mach F, Baigent C, Catapano AL, Koskinas KC, Casula M, et al. 2019 ESC/EAS Guidelines for the management of dyslipidaemias: lipid modification to reduce cardiovascular risk: the Task Force for the management of dyslipidaemias of the European Society of Cardiology (ESC) and European Atherosclerosis Society (EAS). Eur Heart J 2020;41(1):111-88. https://doi.org/ 10.1093/eurheartj/ehz455.

[5] K. Kotseva, G.D. Backer, D.D. Bacquer, L. Ryden, A. Hoes et al., Lifestyle and impact on cardiovascular risk factor control in coronary patients across 27 countries: results from the European Society of Cardiology ESC-EORP EUROASPIRE V registry, European Journal of Preventive Cardiology. 26 (8) 824-835. doi:10.1177/2047487318825350.

[6] Eckel RH, Grundy SM, Zimmet PZ. The metabolic syndrome. Lancet 2005;365: 1415-28. https://doi.org/10.1016/S0140-6736(05)66378-7.

[7] Isomaa B, Almgren P, Tuomi T, Forsen B, Lahti K, et al. Cardiovascular morbidity and mortality associated with the metabolic syndrome. Diabetes Care 2001;24:683-9. https://doi.org/10.2337/diacare.24.4.683.

[8] Gami AS, Witt BJ, Howard DE, Erwin PJ, Gami LA, et al. Metabolic syndrome and risk of incident cardiovascular events and death: a systematic review and meta-analysis of longitudinal studies. J Am Coll Cardiol 2007;49(4):403-14. https://doi.org/10.1016/j.jacc.2006.09.032.

[9] Olmastroni E, Shlyakhto EV, Konradi AO, Rotar OP, Alieva AS, et al. Epidemiology of cardiovascular risk factors in two population-based studies. Atherosclerosis Suppl 2018;35:14-20. https://doi.org/10.1016/ j.atherosclerosissup.2018.08.003.

[10] Shalnova SA, Deev AD, Metelskaya VA, Evstifeeva SE, Rotar OP, et al. Awareness and statin therapy in patients with various cardiovascular risk. By the data from ECCD. Cardiovasc Ther Prev 2016;15(4):29-37. https://doi.org/ 10.15829/1728-8800-2016-4-29-37.

[11] Olmastroni E, Baragetti A, Casula M, Grigore L, Pellegatta F, et al. Multilevel models to estimate carotid intima-media thickness curves for individual cardiovascular risk evaluation. Stroke 2019;50:1758-65. https://doi.org/ 10.1161/STROKEAHA.118.024692.

[12] Baragetti A, Knoflach M, Cuccovillo I, Grigore L, Casula M, et al. Pentraxin 3 (PTX3) plasma levels and carotid intima media thickness progression in the general population. Nutr Metabol Cardiovasc Dis 2014;24(12):38-9. https:// doi.org/10.1016/j.numecd.2014.08.011.

[13] Alberti KGMM, Eckel RH, Grundy SM, Zimmet PZ, Cleeman JI, et al. Harmonizing the metabolic syndrome: a joint interim statement of the international diabetes federation task force on Epidemiology and prevention; national heart, lung, and blood Institute; American heart association; world heart federation; international atherosclerosis society; and international association for the study of obesity. Circulation 2009;120(16):1640-5. https://doi.org/ 10.1161/circulationaha.109.192644.

[14] Conroy RM, Pyorala K, Fitzgerald AP, Sans S, Menotti A, et al. Estimation of ten-year risk of fatal cardiovascular disease in Europe: the SCORE project. Eur Heart J 2003;24(11):987-1003. https://doi.org/10.1016/s0195-668x(03) 00114-3.

[15] Townsend N, Wilson L, Bhatnagar P, Wickramasinghe K, Rayner M, et al. Cardiovascular disease in Europe: epidemiological update 2016. Eur Heart J 2016;37(42):3232-45. https://doi.org/10.1093/eurheartj/ehw334.

[16] Volpe M, Battistoni A, Gallo G, Rubattu S, Tocci G. Executive summary of the 2018 joint consensus document on cardiovascular disease prevention in Italy. High Blood Pres Cardiovasc Prev 2018;25(3):327-41. https://doi.org/10.1007/ s40292-018-0278-8.

[17] Cuspidi C, Sala C, Provenzano F, Tadic M, Gherbesi E, et al. J Hypertens 2018;36(1):23-30. https://doi.org/10.1097/HJH.0000000000001575.

[18] Miccoli R, Bianchi C, Odoguardi L, Penno G, Caricato F, et al. Nutr Metabol Cardiovasc Dis 2005;15(4):250-4. https://doi.org/10.1016/ j.numecd.2004.09.002.

[19] Tocci G, Ferrucci A, Bruno G, Mannarino E, Nati G, et al. Cardiovasc Diagn Ther 2015;5(4):271-9. https://doi.org/10.3978/j.issn.2223-3652.2015.07.03.

[20] Takahashi MM, de Oliveira EP, de Carvalho ALR, de Souza Dantas LA, Fhp Burini, Portero-McLellan KC, Burini RC. Metabolic syndrome and dietary components are associated with coronary artery disease risk score in freeliving adults: a cross-sectional study. Diabetol Metab Syndrome 2011;3(1): $1-7$. 